\title{
Marginal adaptation of ceramic and composite inlays in minimally invasive mod cavities
}

\author{
Zaruba, M ; Kasper, R ; Kazama, R ; Wegehaupt, F J ; Ender, A ; Attin, T ; Mehl, A
}

\begin{abstract}
OBJECTIVES: This study aims to evaluate the effect of a minimally invasive mesial-occlusaldistal (mod) preparation on the marginal adaptation of ceramic and composite inlays with the aim of saving sound dental substance. MATERIALS AND METHODS: Class II mod cavities were prepared in 50 extracted human molars and randomly allocated to five groups $(\mathrm{n}=10)$. In all groups, the mesialproximal box margins were located in the dentin, $1 \mathrm{~mm}$ below the cementoenamel junction (CEJ), while the distal box margins were $1 \mathrm{~mm}$ above the CEJ. In groups A and B, conventional standard preparations with a divergent angle of $=6^{\circ}$ were prepared. In groups C, D, and E, minimally invasive standard preparations with a convergent angle of $=10^{\circ}$ were prepared. In groups $\mathrm{A}$ and $\mathrm{D}$, composite inlays and, in groups $\mathrm{B}$ and $\mathrm{C}$, ceramic inlays were fabricated (chairside economical restoration of esthetic ceramics (CEREC)) and adhesively inserted. In group E, a direct composite filling using the incremental technique was placed. Replicas were taken before and after thermomechanical loading $\left(1,200,000\right.$ cycles, $50 / 5{ }^{\circ} \mathrm{C}$, max. load $49 \mathrm{~N}$ ). Marginal integrity (tooth-luting composite, luting composite-inlay) was evaluated by scanning electron microscopy $(\times 200)$. The percentage of continuous margins in the different locations was compared between and within groups before and after cycling, using ANOVA and Scheffé post hoc test. RESULTS: After the thermomechanical loading, no significant differences were observed between the different groups with respect to the interface of luting composite-inlay. At the interface of toothluting composite for preparations involving the dentin, groups A and B behaved significantly better compared to the control group $\mathrm{E}$, which in turn were not different to groups $\mathrm{C}$ and D. CONCLUSION: Composite and ceramic inlays inserted in minimally invasive prepared mod cavities result in margins not different from those of inlays placed in conventional mod preparations. Direct composite filling margins, however, were inferior to those attained by conventional indirect restorations. CLINICAL RELEVANCE: Minimally invasive preparations for mod inlays with undercuts show marginal adaptation equal to that of conventional inlay preparation design.
\end{abstract}

DOI: https://doi.org/10.1007/s00784-013-0988-1

Posted at the Zurich Open Repository and Archive, University of Zurich ZORA URL: https://doi.org/10.5167/uzh-87925

Journal Article

Published Version

Originally published at:

Zaruba, M; Kasper, R; Kazama, R; Wegehaupt, F J; Ender, A; Attin, T; Mehl, A (2014). Marginal adaptation of ceramic and composite inlays in minimally invasive mod cavities. Clinical Oral Investigations, 18(2):579-587.

DOI: https://doi.org/10.1007/s00784-013-0988-1 


\title{
Marginal adaptation of ceramic and composite inlays in minimally invasive mod cavities
}

\author{
M. Zaruba • R. Kasper • R. Kazama • F. J. Wegehaupt • \\ A. Ender • T. Attin $\cdot$ A. Mehl
}

Received: 22 May 2012 / Accepted: 8 April 2013 /Published online: 1 May 2013

(C) Springer-Verlag Berlin Heidelberg 2013

\begin{abstract}
Objectives This study aims to evaluate the effect of a minimally invasive mesial-occlusal-distal (mod) preparation on the marginal adaptation of ceramic and composite inlays with the aim of saving sound dental substance.

Materials and methods Class II mod cavities were prepared in 50 extracted human molars and randomly allocated to five groups $(n=10)$. In all groups, the mesial-proximal box margins were located in the dentin, $1 \mathrm{~mm}$ below the cementoenamel junction (CEJ), while the distal box margins were $1 \mathrm{~mm}$ above the CEJ. In groups A and B, conventional standard preparations with a divergent angle of $\alpha=6^{\circ}$ were prepared. In groups $\mathrm{C}, \mathrm{D}$, and $\mathrm{E}$, minimally invasive standard preparations with a convergent angle of $\alpha=10^{\circ}$ were prepared. In groups $\mathrm{A}$ and $\mathrm{D}$, composite inlays and, in groups $\mathrm{B}$ and $\mathrm{C}$, ceramic inlays were fabricated (chairside economical restoration of esthetic ceramics (CEREC)) and adhesively inserted. In group $\mathrm{E}$, a direct composite filling using the incremental technique was placed. Replicas were taken before and after thermomechanical loading $\left(1,200,000\right.$ cycles, $50 / 5{ }^{\circ} \mathrm{C}$, max. load $\left.49 \mathrm{~N}\right)$. Marginal integrity (tooth-luting composite, luting composite-inlay) was evaluated by scanning electron microscopy $(\times 200)$. The percentage of continuous margins in the different locations was compared between and within groups before and after cycling, using ANOVA and Scheffé post hoc test.
\end{abstract}

M. Zaruba $(\bowtie) \cdot$ R. Kasper $\cdot$ F. J. Wegehaupt $\cdot$ A. Ender $\cdot$

T. Attin $\cdot$ A. Mehl

Clinic for Preventive Dentistry, Periodontology and Cariology,

University of Zurich, Plattenstrasse 11,

CH-8032, Zurich, Switzerland

e-mail: markus.zaruba@zzm.uzh.ch

R. Kazama

Removable Partial Prosthodontics,

Department of Masticatory Function Rehabilitation,

Division of Oral Health Sciences, Graduate School,

Tokyo Medical and Dental University, Tokyo, Japan
Results After the thermomechanical loading, no significant differences were observed between the different groups with respect to the interface of luting composite-inlay. At the interface of tooth-luting composite for preparations involving the dentin, groups A and B behaved significantly better compared to the control group $\mathrm{E}$, which in turn were not different to groups $\mathrm{C}$ and $\mathrm{D}$.

Conclusion Composite and ceramic inlays inserted in minimally invasive prepared mod cavities result in margins not different from those of inlays placed in conventional mod preparations. Direct composite filling margins, however, were inferior to those attained by conventional indirect restorations.

Clinical relevance Minimally invasive preparations for mod inlays with undercuts show marginal adaptation equal to that of conventional inlay preparation design.

Keywords Composite inlay $\cdot$ Ceramic inlay $\cdot$ Minimally invasive $\cdot$ Marginal adaption

\section{Introduction}

The present study evaluated the effect of minimally invasive mesial-occlusal-distal (mod) preparations with undercuts on the marginal adaptation of composite and ceramic inlays, with the aim of saving healthy dental substance.

Since the introduction of adhesive technology in dentistry [1], Black's guideline of extension for prevention has changed to "prevention instead of extension" [2]. Adhesive systems, allow for new cavity designs to be used with composite materials [3], as they no longer require a special retention form as do amalgam or metal inlay restorations. Attention can now be focused on maximal preservation of dental hard tissue, and a minimally invasive design should be selected for the given situation. This is especially 
advantageous in cases of lost or failed restorations. Removal of sound dental hard tissue can be avoided in these situations by using a minimally invasive preparation procedure, thereby increasing the longevity of the tooth.

Resin composites have undergone enormous development since their first use in dentistry in the 1950s by Buonocore [1, 4]. With improved wear resistance, strength, esthetics, and reduced water absorption in comparison to previous materials, composite fillings are increasingly being placed in posterior, as well as anterior, areas of the mouth [5]. Nevertheless, polymerization shrinkage [6-8] and microleakage [9] of resin-based restorative materials remain unsolved problems in clinical dentistry. Due to shrinkage, especially in direct class II adhesive restorations, incremental methods [10-14], the use of ceramic inserts [15], or the application of a base [12, 16] have been suggested to counteract this polymerization shrinkage and to reduce stress development within the tooth restoration system. Polymerization shrinkage is influenced by different parameters [17], such as material properties [18], configuration factor $[19,20]$, cavity size, presence or absence of enamel at cavity margins, and the dentin quality, morphology, and location [21, 22]. Especially in larger cavity sizes, the indirect restoration technique could help in reducing the polymerization contraction, which is restricted to the thin composite cement layer [23].

As an indirect technique, $\mathrm{CAD} / \mathrm{CAM}$ restorations, such as the chairside economical restoration of esthetic ceramics (CEREC) restoration process, come into consideration [24], showing a survival rate comparable to casted gold restorations [4, 25-27]. To date, special industrially fabricated ceramic blocks are used with the CEREC system. But more recently, composite blocks [28] have demonstrated great potential, limiting the risk of cuspal fracture below the cementoenamel junction (CEJ) when compared to porcelain onlays [29, 30].

Using composite resin blocks in $\mathrm{CAD} / \mathrm{CAM}$ procedures may present an additional advantage in terms of milling time and conservation of tooth structure. Physical properties allow milling in thin layers [31], which may be advantageous in restoring primary teeth and also for substitution of, for example, amalgam fillings or indirect gold restorations. In addition, the prefabricated blocks are industrially fabricated and highly homogeneous, which should improve the mechanical properties and, therefore, the performance of the restoration over time compared to direct filling procedures [28].

To date, various preparation guidelines exist for inlay restorations [24, 32-34]. Especially for ceramic inlays, a cavity angle of approximately $6^{\circ}$ to $10^{\circ}$ is recommended. Therefore, sound tooth structure might be sacrificed to achieve a conventional divergent geometrical design. Especially the more coronally located parts of the cavity have to be removed. So, while an undermined preparation design would save sound tissue, it would also lead to a broader luting margin cervically.
Due to of the abovementioned considerations, this study was designed to evaluate the effect of a minimally invasive mod preparation design with undercuts on the marginal adaptation of direct composite fillings, composite inlays, and ceramic inlays, and compare them to conventional divergent preparations. The null hypothesis tested in this study is that there will be no difference in marginal adaptation between the different preparation designs and materials used.

\section{Materials and methods}

\section{Sample preparation}

Fifty intact, caries-free human molars with completed root formation, which were stored in $0.1 \%$ thymol solution between extraction and use, were selected for this in vitro test. Extracted teeth were collected as anonymous by-products of regular therapy. According to that, our Medical Ethical Board stated that the performed research was not conducted under the regulations of the "Act on Medical Research Involving Human Subjects" (METc 2009.305). Therefore, a written informed consent was not required. Before treatment, patients were informed about the general research purposes and gave verbal agreement, which was not documented to keep the procedures anonymously. After cleaning, the molars were randomly assigned to five experimental groups $(n=10)$. All teeth were prepared for the simulation of pulpal pressure according to a protocol described by Krejci et al. [35]. The roots of the teeth were centrally mounted to roughened specimen carriers (SEM mounts, Bal-Tec AG, Balzers, Liechtenstein) with a superglue (Renfert Sekundenkleber Nr 1733, Dentex AG, Zürich) and embedded in auto-polymerizing resin (Paladur, Heraeus Kulzer, Wehrheim, Germany). Intrapulpal pressure was maintained at $25 \mathrm{mmHg}$ throughout the whole experiment, i.e., during cavity preparation, restoration placement, finishing, and thermomechanical loading (TML). For the standard preparations, a drilling machine (Proxxon BFW 40/E, Niersbach, Germany) with a specially developed holder, adjustable in all three dimensions, was used. In groups A and $\mathrm{B}$, standardized non-beveled mod class II cavities with a divergent angle of $6^{\circ}$ were prepared using 46- $\mu \mathrm{m}$ diamond burs (ISO 80610472514040, Busch, Engelskirchen, Germany) under water cooling. For the minimally invasive convergent preparations, a special bur was turned of carbide metal and coated with $46-\mu \mathrm{m}$ diamonds (Intensiv SA, Grancia, Switzerland). All diamond burs were $4 \mathrm{~mm}$ in diameter at the working end. Firstly, the tooth was adjusted with its occluso-apical axis perpendicular to the bottom. Based on the deepest point of the fissure, the bur was positioned $2.5 \mathrm{~mm}$ deeper at the proximal side, and the occlusal box was ground. Thereafter, the mesial box was ground $1 \mathrm{~mm}$ below the CEJ (Fig. 1), and the distal box, $1 \mathrm{~mm}$ above the 
Fig. 1 Description of experimental groups A-E prepared also in the dentin
Groups

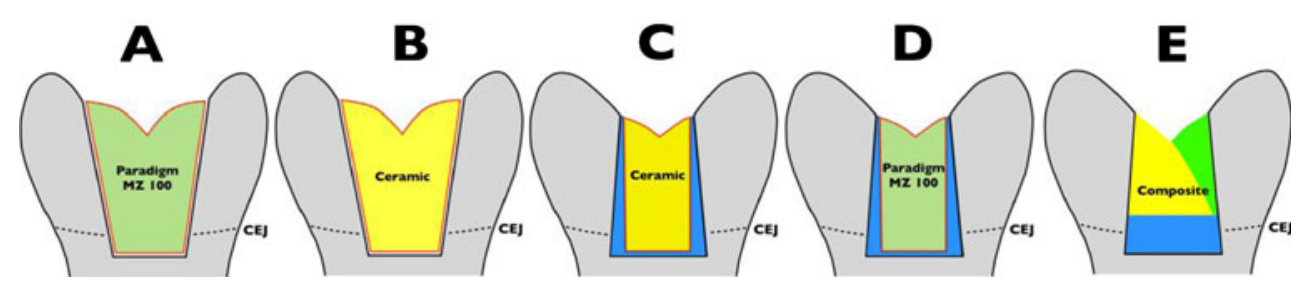

CEJ (Fig. 2). Afterwards, all inner line angles of the cavities were smoothed under $\times 12$ magnification (Stemi 2000, Carl Zeiss; Feldbach, Switzerland) using a $25-\mu \mathrm{m}$ diamond bur (Intensiv SA) and a hand piece under water cooling. Additionally, for the composite group E, the proximal margins were beveled using an ultrasonic device [36] (miniPiezon ${ }^{\circledR}$, EMS, Nyon, Switzerland). Only one optical impression of each preparation in groups $\mathrm{A}, \mathrm{B}, \mathrm{C}$, and $\mathrm{D}$ was performed, and virtual mod inlays were constructed using the CEREC AC Bluecam (Sirona, Bensheim, Germany) with the software version V3.80. In groups B and C, inlays were milled from prefabricated leucite-reinforced glass ceramic blocks (IPS Empress CAD, LTC2, Ivoclar Vivadent, Schaan, Liechtenstein), and in groups $\mathrm{A}$ and $\mathrm{D}$, from industrially produced composite blocks (Paradigm MZ100, B3, 3 M ESPE, St. Paul, MN, USA) with a CEREC milling machine (MCXL, Sirona). The fit of the ceramic inlays into the respective cavity was controlled with a low viscosity polyvinylsiloxane (Fit Checker, GC, Tokyo, Japan) and stereomicroscope (Stemi 2000, Carl Zeiss) at $\times 12$ magnification. For cementation, all cavities were totally etched (enamel, $30 \mathrm{~s}$; dentin, $15 \mathrm{~s}$ ) with $35 \%$ phosphoric acid (Ultra-etch, Ultradent, South Jordan, UT, USA) and rinsed with water for $40 \mathrm{~s}$ and followed by drying with oil-free air. Then, the adhesive system (Syntac Primer, Syntac Adhesive, Heliobond, Ivoclar Vivadent) was applied according to the manufacturer's instructions. The bonding was light-cured for $40 \mathrm{~s}$ (mode: HIP, 1,200 mW/ $\mathrm{cm}^{2}$; Bluephase, Ivoclar Vivadent). The surface conditioning of the milled composite restorations included airborne-particle abrasion with $50 \mu \mathrm{m}$ aluminum oxide followed by cleaning using $35 \%$ phosphoric acid (Ultra-etch, Ultradent) with a gentle brushing motion for $1 \mathrm{~min}$, rinsing with water for $20 \mathrm{~s}$, and subsequent silanization (Monobond-S, Ivoclar Vivadent) for
$60 \mathrm{~s}$. The internal surface of the ceramic inlays were first cleaned with alcohol and then etched for $60 \mathrm{~s}$ with $5 \%$ hydrofluoric acid (Vita Ceramics Etch, Vita Zahnfabrik, Bad Säckingen, Germany). After $60 \mathrm{~s}$ of rinsing and drying, a coupling silane (Monobond-S, Ivoclar Vivadent) was applied and left undisturbed for $60 \mathrm{~s}$, followed by air-drying. Afterwards, a thin layer of bonding resin (Heliobond, Ivoclar Vivadent) was applied onto the inner surface of the restorations. The inlays were first manually and then ultrasonically seated with a nanohybrid composite (Filtek Supreme XT, XWB, $3 \mathrm{M}$ ESPE), which was preheated for $5 \mathrm{~min}$ to $37^{\circ} \mathrm{C}$ (Calset, AdDent, Danbury, CT, USA). With a dental probe, excess material was carefully removed, and finally, all margins were covered with glycerin gel (Airblock, DENTSPLY DeTrey GmbH, Konstanz, Germany) to avoid oxygeninhibited layer formation. Each side (mesio- and distobuccal/ mesio- and disto-lingual/mesio- and disto-occlusal) was light-cured for $40 \mathrm{~s}$ with a polymerisation light (mode: $\mathrm{HIP}, 1,200 \mathrm{~mW} / \mathrm{cm}^{2}$; Bluephase, Ivoclar Vivadent) as proposed by Lutz et al. [12]. For controlling the light output of the LED device, a radiometer (Optilux Radiometer, SDS Kerr; Orange, CA, USA) was used to prove that the power was always above $1,000 \mathrm{~mW} / \mathrm{cm}^{2}$. In group $\mathrm{E}$, an incremental direct filling technique was used. First, the proximal boxes were restored with three increments for each box. Then one buccal and one lingual increment of the occlusal side were placed. Each increment was light-cured for $40 \mathrm{~s}$ using the same polymerisation light. All restorations were finished with $15-\mu \mathrm{m}$ fine diamond burs (Intensiv SA) and polishing disks (Soflex, 3 M ESPE, Rüschlikon, Switzerland) under continuous water cooling and descending roughness. The polishing procedure was observed under a stereomicroscope (Stemi 2000, Carl Zeiss) at $\times 12$ magnification.
Fig. 2 Description of experimental groups $\mathrm{A}^{+}-\mathrm{E}^{+}$ prepared only in the enamel

\section{Groups}

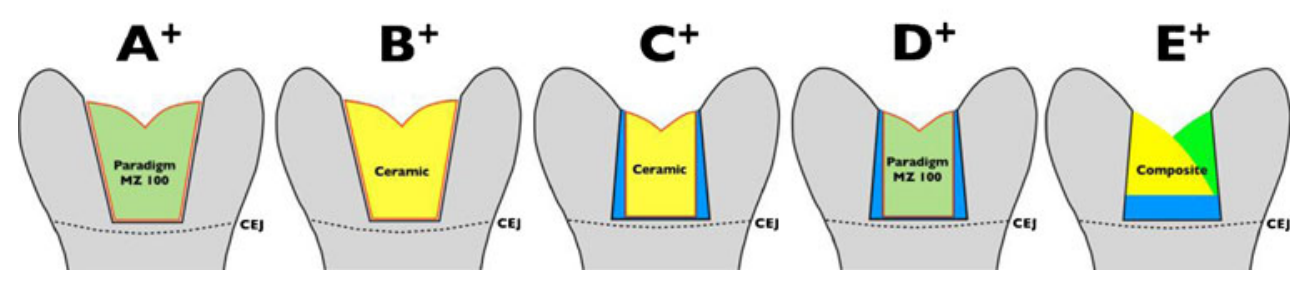




\section{Thermomechanical loading}

For TML, mesio-palatinal cusps of human maxillary cariesfree molars were separated, embedded in amalgam (Dispersalloy, DENTSPLY DeTrey $\mathrm{GmbH}$ ), and fixed onto a carrier [37]. These samples were later used as antagonists. The antagonists were stored in water during the whole experiment to avoid desiccation [38]. Then, they were mounted together with the specimen in the sample chambers of the TML machine. The occlusal contacts were marked with articulating paper to ensure that the loading area was in the center of the occlusal inlay surface, not contacting the margins of the preparations. All restored teeth were loaded with repeated thermal and mechanical stresses in a computer-controlled masticator (CoCoM 2, PPK, Zürich, Switzerland) for 1.2 Mio cycles with $49 \mathrm{~N}$ at $1.7 \mathrm{~Hz}$. [37-39]. Thermal cycling was carried out during the loading cycles by flushing water with temperature changing 6,000 times from 5 to $50^{\circ} \mathrm{C}$ [40].

Quantitative marginal SEM analysis

Before (initial) and after (terminal) TML, impressions of the mesial and distal boxes were taken using an Apolyvinylsiloxane (President Light Body, Coltène). The impressions were poured out with epoxy resin (Stycast 1266, Emerson \& Cuming, Westerlo, Belgium), glued (Superglue 1733, Renfert, Hilzing, Germany) onto a customized sample carrier, and sputter-coated with gold (Sputer SCD 030, Balzers Union, Balzers, Liechtenstein). All specimens were examined for quantitative marginal analysis with a scanning electron microscope (Amray 1810/T, Amray; Bedford, MA, USA) at $10 \mathrm{kV}$ and $\times 200$ magnification by one examiner, who was blinded with respect to the group assignment of the specimens. Two different interfaces were evaluated for marginal integrity at the proximal cavity walls: first, the interface between tooth and luting composite (tooth-luting composite); and second, the interface between luting composite and inlay (luting composite-inlay). All specimens were examined for "continuous" margins (no gap, no interruption of continuity) and imperfect "noncontinuous" margins (gap due to adhesive or cohesive failure; restoration or enamel fractures related to restoration margins).

For the preparation boxes below the CEJ, the percentage of continuous margins is separated in the margins in the enamel (groups $\mathrm{Ae}-\mathrm{Ee}$ ) and margins in the dentin (groups Ad-Ed). For the preparation boxes located only in the enamel $\left(\mathrm{A}^{+}-\mathrm{E}^{+}\right)$, total values of the percentage of continuous margins are presented.

\section{Statistical analysis}

Marginal quality was expressed as a percentage of continuous margins over the margin length $(100 \%=$ no discontinuous aspects) both before (initial) and after (terminal) TML. Statistical analysis was performed with SPSS (version 16.0, SPSS Inc., Chicago, IL, USA). Differences between groups were tested using analysis of variance and Scheffé post hoc test $(p<0.05)$. Additionally, for each treatment group, the Wilcoxon signed rank test was used to investigate the difference between the initial and the terminal value of the continuous margin $(p<0.05)$.

\section{Results}

Interface of tooth-luting composite of preparations below the CEJ for margins only in the enamel (Ae-Ee)

The percentages of continuous margins in the enamel are given in Fig. 3. Initial percentages of continuous margin of groups Ae (91.2 $\pm 9.4 \%), \mathrm{Be}(89.9 \pm 11.5 \%), \mathrm{Ce}(91.9 \pm 6.1)$, and $\mathrm{Ee}(78.4 \pm 15.5 \%)$ were not statistically and significantly different when compared with each other $(p>0.05$, respectively). Furthermore, no significant difference in the percentages of continuous margin of groups $\mathrm{Ae}, \mathrm{Be}, \mathrm{Ce}$, and De $(91.9 \pm 4.8 \%)(p>0.05$, respectively) was observed. The percentage of continuous margin in group Ee was significantly lower compared to that in group De $(p<0.05)$.

TML led to a significant reduction of continuous margin in groups $\mathrm{Ae}, \mathrm{Ce}, \mathrm{De}$, and $\mathrm{Ee}$, while in group $\mathrm{Be}$, no significantly lower percentage of continuous margin was observed.

After TML, no significant difference in the marginal adaptation was observed ( $p=0.067$ ) between any of the groups.

Interface of tooth-luting composite of preparations below the CEJ with margins for margins only in the dentin (Ad-Ed)

The percentages of continuous margins in the dentin are given in Fig. 4. The percentage of continuous margin in group Ed $(91.9 \pm 4.8 \%)$ was significantly lower compared with that in groups $\mathrm{Ad}(91.5 \pm 12.4 \%), \mathrm{Bd}(85.0 \pm 7.6 \%), \mathrm{Cd}(87.8 \pm$ $9.8 \%)$, and $\operatorname{Dd}(95.6 \pm 1.8 \%)(p<0.05$, respectively). Within the groups $\mathrm{Ad}, \mathrm{Bd}, \mathrm{Cd}$, and $\mathrm{Dd}$, no significant difference in the percentage of continuous margin was found.

TML led to a significantly lower percentage of continuous margin for groups $\mathrm{Ad}, \mathrm{Cd}$, and Dd when compared with the respective initial values ( $p<0.05$, respectively). For the remaining groups, no significant lower percentage of continuous margin was observed.

After TML, no significant difference in the percentage of continuous margin of groups $\mathrm{Ad}(79.8 \pm 27.0 \%)$, Bd (79.9 \pm $16.1 \%), \mathrm{Cd}(77.7 \pm 11.8 \%)$, and $\mathrm{Dd}(72.1 \pm 16.7 \%)$ was found. Group Ed $(49.9 \pm 27.0 \%)$ showed a significantly lower percentage of continuous margin when compared with groups $\mathrm{Ad}$ and $\mathrm{Bd}(p<0.05$, respectively). 
Fig. 3 Continuous margins in the enamel of the interface tooth-luting composite for groups prepared below the CEJ. Percentages (mean $\pm \mathrm{SD}$ ) of continuous margins in experimental groups Ae-Ee as determined initially (In) and terminally (Te) TML in the enamel. Subsets not significantly different are indicated by same superscript letters or numbers, respectively. Asterisks indicate significant differences between In and Te

\section{Interface: tooth-composite}

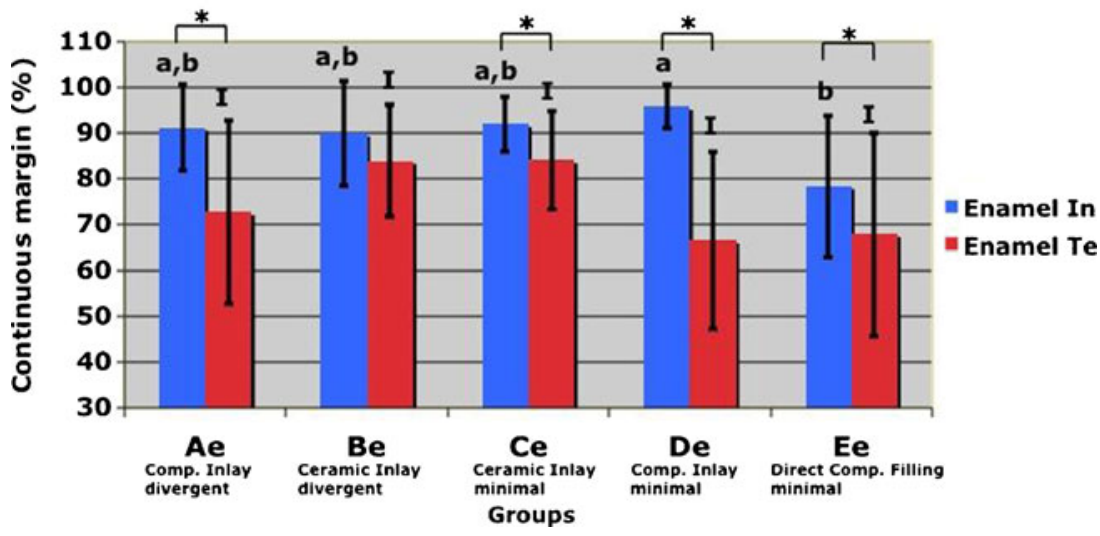

Interface of tooth-luting composite of preparations above the CEJ for margins in the enamel $\left(\mathrm{A}^{+}-\mathrm{E}^{+}\right)$

The percentages of continuous margins in the enamel are given in Fig. 5. Initially, the percentage of continuous margin in group $\mathrm{E}^{+}(82.4 \pm 8.6 \%)$ was significantly lower when compared with the groups $\mathrm{A}^{+}(94.5 \pm 5.8 \%), \mathrm{B}^{+}(94.2 \pm 6.0 \%)$, and $\mathrm{D}^{+}(94.0 \pm$ $4.0 \%$ ). Groups $\mathrm{A}^{+}, \mathrm{B}^{+}, \mathrm{C}^{+}$, and $\mathrm{D}^{+}$were not significantly different when compared with each other $(p>0.05$, respectively). For all groups, except group $\mathrm{C}^{+}$, the TML led to a significant reduction of the percentages of continuous margin ( $p<0.05$, respectively).

After TML, the percentages of continuous margin of groups $\mathrm{A}^{+}(73.8 \pm 17.2 \%), \mathrm{B}^{+}(85.6 \pm 8.8 \%), \mathrm{C}^{+}(89.9 \pm$ $6.0 \%)$, and $\mathrm{D}^{+}(79.5 \pm 16.8 \%)$ were not significantly different. In group $\mathrm{E}^{+}(69.8 \pm 15.3 \%)$, a significantly lower percentage of continuous margin was observed when compared with group $\mathrm{C}^{+}$.

Interface of luting composite-inlay

Due to the direct composite filling treatment in group E, no evaluation was performed for this interface. For all other treatment groups, no statistically significant influence on the percentage of continuous margins was observed at terminal evaluation ( $p>0.05$, respectively).

\section{Discussion}

The purpose of this study was to evaluate the effect of a minimally invasive mod preparation on the marginal adaptation of composite and ceramic inlays, with the aim of saving sound tooth structure. In this in vitro study, all specimens were evaluated by SEM after TML. To simulate the clinical environment, an especially developed well-proven chewing machine with additional artificial aging through thermocycling was used [37, 41, 42]. The advantage of this method is a reproducible standardized stress for all specimens. In addition, intrapulpal pressure was used to simulate physiological conditions [43]. Therefore, it could be assumed that the results of this study might have a certain clinical relevance. However, TML is influenced by a number of factors, including applied force, force profile, contact time, sliding movement, and clearance of worn material. These factors are not controlled in every phase of the simulation [44].

It must be considered in our study that only one brand of composite for luting and direct restoration was used.
Fig. 4 Continuous margins in the dentin of the interface tooth-luting composite for groups prepared below the CEJ. Percentages (mean \pm SD) of continuous margins in experimental groups Ad-Ed as determined initially (In) and terminally (Te) TML in the dentin. Subsets not significantly different are indicated by same superscript letters or numbers, respectively. Asterisks indicate significant differences between In and $\mathrm{Te}$

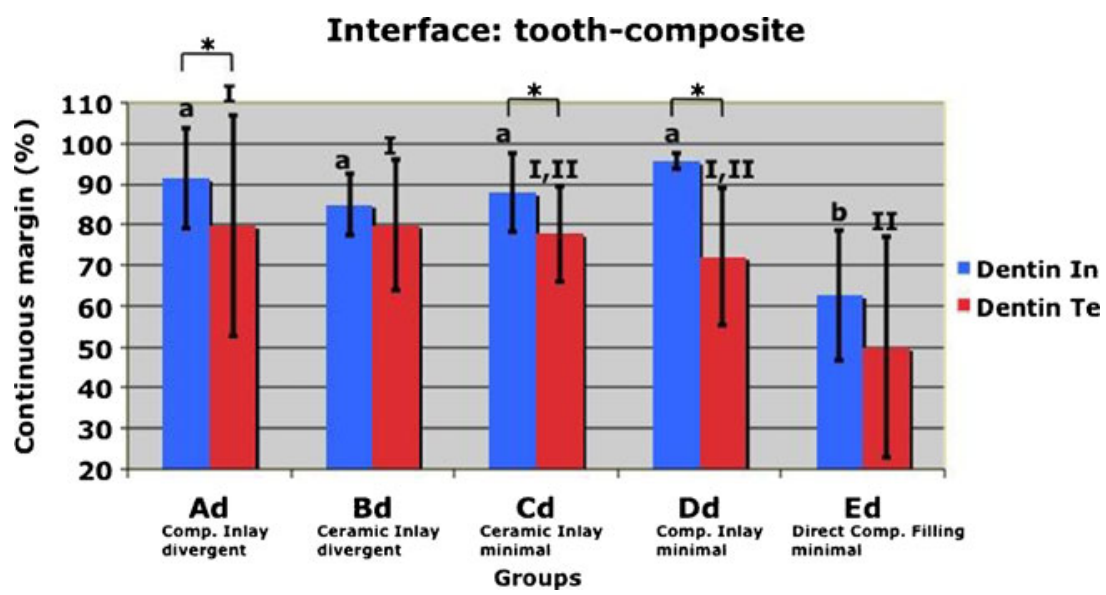


Fig. 5 Continuous margins in the enamel of the interface tooth-composite for groups prepared above the CEJ. Percentages (mean \pm SD) of continuous margins in experimental groups $\mathrm{A}^{+}-\mathrm{E}^{+}$as determined initially (In) and terminally (Te) TML in the enamel. Subsets not significantly different are indicated by same superscript letters or numbers, respectively. Asterisks indicate significant differences between In and Te

\section{Interface: tooth-composite}

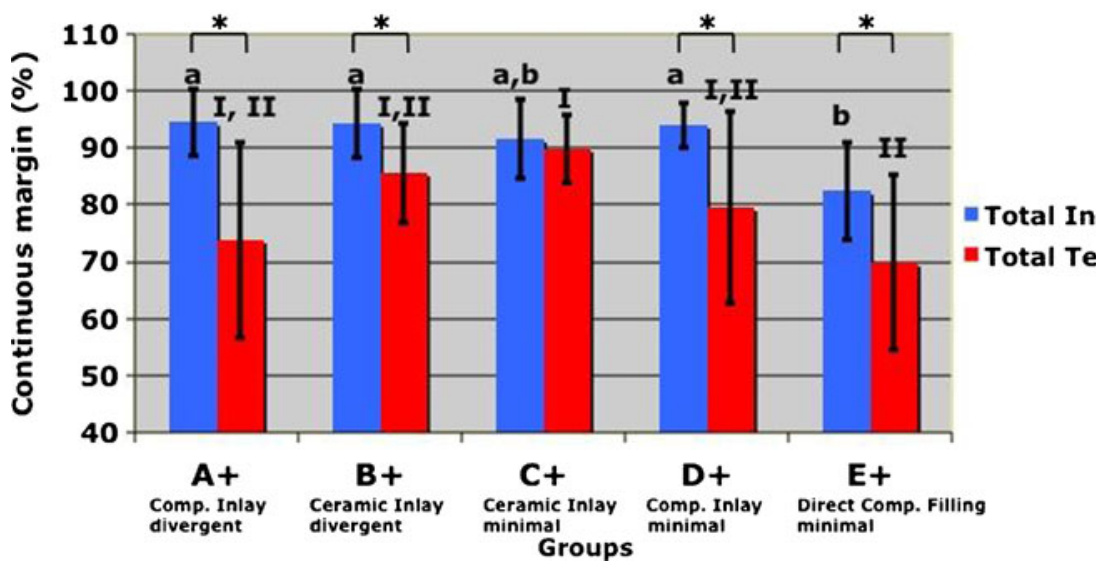

Generally, luting composites, even of similar composition, can differ considerably in their chemical and physical characteristics [45, 46] and are, hence, affected in different ways by light polymerization [47]. In addition, the use of a highly filled and viscous composite for luting the restoration has obvious advantages since it does not flow over all surfaces and may be easily removed with a probe, spatula, or floss. This is a critical step in the cementation process and for removing the remaining overhangs. For the clinical procedure, we recommend to use a spatula with gentle sliding motions always parallel to the surface, starting from the inner proximal cervical parts to the lateral more occlusal box margins. For easier handling and better cervical marginal adaptation [48], a nanofilled luting composite was preheated to $37^{\circ} \mathrm{C}$ prior to insertion to reduce the viscosity [49]. The temperature chosen in this study was similar to that of the oral cavity. With higher temperatures $\left(T>37^{\circ} \mathrm{C}\right)$, increased cuspal movement has been observed [50], leading to a greater challenge on the bond to tooth interface. Additionally, higher final monomer conversion values can be achieved with preheated composite, thereby reducing the amount of unreacted monomer, which may potentially leach into the oral cavity [51].

Before TML, a good marginal fit was achieved by all indirect restorations for the tooth-composite margin. This is in accordance with the literature $[52,53]$. After TML, a reduction of the percentage of continuous margin could be observed in all groups. This finding demonstrates that the marginal adaptation of adhesively inserted restorations disintegrates through TML $[42,54-56]$.

In the groups (Ae-Ee) with additional preparations in the dentin, no significant differences $(p<0.05)$ between all groups for margins located in the enamel could be detected after TML. In the literature, larger proportions of enamel microfractures were observed in in vitro mechanical loading tests conducted on cavities with a butt margin design [55, 57-59]. The parallel orientation of enamel prisms in the axial wall, in combination with the weakened region of non-beveled enamel after phosphoric acid conditioning, could be an explanation for these findings and may lead to a reduction of marginal adaptation after TML.

For the groups with preparations extending into the dentin, the conventionally prepared cavity groups $\mathrm{Ad}$ and $\mathrm{Bd}$ showed significantly higher values $(p<0.05)$ at the toothluting composite margin when compared with the direct composite group Ed but not significantly in comparison with the minimally invasive preparations with ceramic (group Cd) or composite inlays (group Dd). Therefore, the null hypothesis must be rejected. The lower values of continuous margins in the direct composite fillings may be attributed to polymerization shrinkage, which remains an unavoidable problem and may compromise the integrity and longevity of posterior restorations [60], particularly those with margins in the dentin [61]. Additionally, the potential for marginal gaps and microleakage increases with cavosurface margins in the dentin due to the biological variability of this tissue [62]. To minimize the adverse effects of polymerization shrinkage, an incremental placement technique was performed [43, 63].

CEREC 3 restorations exhibit a luting space, which is less than $100 \mu \mathrm{m}[26,64]$. This might have led to a reduction of the polymerization shrinkage, especially in the groups with a conventional preparation including angles of approximately $\alpha=6^{\circ}$. However, a large cementing space partially compensates for the polymerization stresses, allowing the tooth structure and the restoration to undergo micro movements during the luting procedure [65-67]. However, these observations are in contrast to the findings of Manhart et al. [68], where almost perfect marginal adaptation in class II mod enamel cavities were reported after loading when direct composite, composite inlays, and ceramic inlays were used as filling or restoration materials. In the study by Manhart [68], different loading conditions (only 50,000 cycles against 1.2 million in the present study) as well as no dentinal fluid simulation were used, which may have influenced the results. In addition, Manhart 
considered other cavity configurations, which may play an important role in the absorption and distribution of mechanical stresses.

All composite and ceramic inlay groups $\left(\mathrm{A}^{+}-\mathrm{D}^{+}\right)$showed similar values of continuous margin for preparations above the CEJ $(p>0.05)$ at the tooth-luting composite margin. In group $\mathrm{C}^{+}$, significantly higher percentages of continuous margin were observed when compared with the direct filling in group $\mathrm{E}^{+}$. These results are in agreement with those of recent investigations [69-71].

The lower Young;s modulus of composites might be responsible for this observation [72]. In the case of Paradigm MZ, the results could be transferable to Lava ${ }^{\mathrm{TM}}$ Ultimate (3 M ESPE, Seefeld, Germany) due to the similar mechanical properties like Young's modulus. Ceramic restorations provide a higher modulus of elasticity that reduces deformation of the tooth and, therefore, deformations at the margin of the restoration [73].

In the present study, only one optical impression was performed for the indirect inlay restorations. This strategy was chosen to take into account that the fabrication of several optical impressions of the preparation with the current software (V3.80 and SW4.0) would lead to undercuts in the afterwards matched virtual model. The existence of these undercuts would result in the fabrication of inlays which could not be inserted into the cavity. For undercuts inside the preparation, however, the software automatically blocks out the undercuts with respect to the selected insertion axis. Due to these facts, only one optical impression was performed. With this method, the software automatically interpolates the missing data of the undercuts referring to the axis of the optical impression, resulting in a calculated virtual model without undercuts. Accordingly, a special software mode for undercuts with the option of multiple optical impressions would be desirable. Additionally, less loss of dental hard tissue, especially in the occlusal and proximal parts, offers the advantage that more information can be extracted for the biogeneric software $[74,75]$ and, as a side effect, a better occlusal morphology of the restoration may be designed.

Considering traditional principles of fixed prosthodontics, full crown coverage is often recommended to strengthen the remaining tooth substance. When compared to bonded restorations, traditional full crown coverage restorations, however, require a sacrifice of more dental hard tissue $[76,77]$. Additionally, full crown reconstructions are more frequently associated with gingival inflammation and secondary caries [78]. With the method described, replacement of cusps is not always necessary, and preservation of sound dental hard tissue is possible. Especially with chairside $\mathrm{CAD} / \mathrm{CAM}$ methods, an additional advantage is the availability of an optimal dentinal substrate, allowing adhesion to freshly cut dentin without contamination by temporary cements [79-81].

\section{Conclusion}

Within the limits and considerations of this in vitro study, the minimally invasive preparation approach with proximal undercuts for composite and ceramic inlays showed no differences concerning marginal adaptation when compared with the conventional divergent preparations and should be considered as an alternative in clinical practice.

Conflict of interests The authors declare they have no conflicts of interest.

\section{References}

1. Buonocore MG (1955) A simple method of increasing the adhesion of acrylic filling materials to enamel surfaces. J Dent Res 34:849-853

2. Staehle HJ (1999) Minimally invasive restorative treatment. J Adhes Dent 1:267-284

3. Nandini S (2010) Indirect resin composites. J Conserv Dent 13:184 194

4. Manhart J, Chen H, Hamm G, Hickel R (2004) Buonocore Memorial Lecture. Review of the clinical survival of direct and indirect restorations in posterior teeth of the permanent dentition. Oper Dent 29:481-508

5. Willems G, Lambrechts P, Braem M, Vanherle G (1993) Composite resins in the 21st century. Quintessence Int 24:641-658

6. Lu H, Stansbury JW, Dickens SH, Eichmiller FC, Bowman CN (2004) Probing the origins and control of shrinkage stress in dental resin-composites: I. Shrinkage stress characterization technique. J Mater Sci Mater Med 15:1097-1103

7. Peutzfeldt A, Asmussen E (2004) Determinants of in vitro gap formation of resin composites. J Dent 32:109-115

8. Stavridakis MM, Lutz F, Johnston WM, Krejci I (2003) Linear displacement and force induced by polymerization shrinkage of resin-based restorative materials. Am J Dent 16:431-438

9. Roulet JF, Salchow B, Wald M (1991) Margin analysis of posterior composites in vivo. Dent Mater 7:44-49

10. Lutz F, Kull M (1980) The development of a posterior tooth composite system, in-vitro investigation. SSO Schweiz Monatsschr Zahnmed 90:455-483

11. Lutz F, Krejci I, Luescher B, Oldenburg TR (1986) Improved proximal margin adaptation of class II composite resin restorations by use of light-reflecting wedges. Quintessence Int 17:659-664

12. Lutz F, Krejci I, Oldenburg TR (1986) Elimination of polymerization stresses at the margins of posterior composite resin restorations: a new restorative technique. Quintessence Int 17:777-784

13. Weaver WS, Blank LW, Pelleu GBJ (1988) A visible-light-activated resin cured through tooth structure. Gen Dent 36:236-237

14. Bertolotti RL (1991) Posterior composite technique utilizing directed polymerization shrinkage and a novel matrix. Pract Periodontics Aesthet Dent 3:53-58

15. Donly KJ, Wild TW, Bowen RL, Jensen ME (1989) An in vitro investigation of the effects of glass inserts on the effective composite resin polymerization shrinkage. J Dent Res 68:1234-1237

16. Friedl KH, Schmalz G, Hiller KA, Mortazavi F (1997) Marginal adaptation of composite restorations versus hybrid ionomer/composite sandwich restorations. Oper Dent 22:21-29 
17. Carvalho RM, Pereira JC, Yoshiyama M, Pashley DH (1996) A review of polymerization contraction: the influence of stress development versus stress relief. Oper Dent 21:17-24

18. Kemp-Scholte CM, Davidson CL (1990) Marginal integrity related to bond strength and strain capacity of composite resin restorative systems. J Prosthet Dent 64:658-664

19. Feilzer AJ, De Gee AJ, Davidson CL (1987) Setting stress in composite resin in relation to configuration of the restoration. $\mathrm{J}$ Dent Res 66:1636-1639

20. Yoshikawa T, Sano H, Burrow MF, Tagami J, Pashley DH (1999) Effects of dentin depth and cavity configuration on bond strength. J Dent Res 78:898-905

21. Perdigao J, Swift EJ (1994) Analysis of dental adhesive systems using scanning electron microscopy. Int Dent J 44:349-359

22. Shono Y, Ogawa T, Terashita M, Carvalho RM, Pashley EL, Pashley DH (1999) Regional measurement of resin-dentin bonding as an array. J Dent Res 78:699-705

23. Wendt SLJ, Leinfelder KF (1990) The clinical evaluation of heattreated composite resin inlays. J Am Dent Assoc 120:177-181

24. Mörmann WH, Brandestini M, Lutz F (1987) The Cerec system: computer-assisted fabrivation of direct ceramic inlays in one session. Quintessenz 38:457-470

25. Reiss B, Walther W (2000) Clinical long-term results and 10-year Kaplan-Meier analysis of Cerec restorations. Int J Comput Dent 3:9 23

26. Fasbinder DJ (2006) Clinical performance of chairside CAD/CAM restorations. J Am Dent Assoc 137(Suppl):22S-31S

27. Zimmer S, Gohlich O, Ruttermann S, Lang H, Raab WH, Barthel CR (2008) Long-term survival of Cerec restorations: a 10-year study. Oper Dent 33:484-487

28. Rusin RP (2001) Properties and applications of a new composite block for CAD/CAM. Compend Contin Educ Dent 22:35-41

29. Magne P, Knezevic A (2009) Simulated fatigue resistance of composite resin versus porcelain $\mathrm{CAD} / \mathrm{CAM}$ overlay restorations on endodontically treated molars. Quintessence Int 40:125-133

30. Magne P, Knezevic A (2009) Influence of overlay restorative materials and load cusps on the fatigue resistance of endodontically treated molars. Quintessence Int 40:729-737

31. Tsitrou EA, van Noort R (2008) Minimal preparation designs for single posterior indirect prostheses with the use of the Cerec system. Int J Comput Dent 11:227-240

32. Ahlers MO, Morig G, Blunck U, Hajto J, Probster L, Frankenberger $\mathrm{R}$ (2009) Guidelines for the preparation of CAD/CAM ceramic inlays and partial crowns. Int J Comput Dent 12:309-325

33. Arnetzl GV, Arnetzl G (2006) Design of preparations for allceramic inlay materials. Int J Comput Dent 9:289-298

34. Puckett BG (1947) The gold inlay: cavity preparation, pattern, casting and finishing. Dent Surv 23:638

35. Krejci I, Kuster M, Lutz F (1993) Influence of dentinal fluid and stress on marginal adaptation of resin composites. J Dent Res $72: 490-494$

36. Krejci I, Dietschi D, Lutz FU (1998) Principles of proximal cavity preparation and finishing with ultrasonic diamond tips. Pract Periodontics Aesthet Dent 10:295-298, quiz 300

37. Krejci I, Reich T, Lutz F, Albertoni M (1990) An in vitro test procedure for evaluating dental restoration systems. 1. A computer-controlled mastication simulator. Schweiz Monatsschr Zahnmed 100:953-960

38. Krejci I, Albertoni M, Lutz F (1990) An in-vitro test procedure for evaluating dental restoration systems. 2. Toothbrush/toothpaste abrasion and chemical degradation. Schweiz Monatsschr Zahnmed 100:1164-1168

39. Krejci I, Lutz F (1990) In-vitro test results of the evaluation of dental restoration systems. Correlation with in-vivo results. Schweiz Monatsschr Zahnmed 100:1445-1449
40. Gohring TN, Besek MJ, Schmidlin PR (2002) Attritional wear and abrasive surface alterations of composite resin materials in vitro. J Dent 30:119-127

41. Gohring TN, Schonenberger KA, Lutz F (2003) Potential of restorative systems with simplified adhesives: quantitative analysis of wear and marginal adaptation in vitro. Am J Dent 16:275-282

42. Manhart J, Schmidt M, Chen HY, Kunzelmann KH, Hickel R (2001) Marginal quality of tooth-colored restorations in class II cavities after artificial aging. Oper Dent 26:357-366

43. Lutz F, Krejci I, Barbakow F (1991) Quality and durability of marginal adaptation in bonded composite restorations. Dent Mater 7:107-113

44. Heintze SD (2006) How to qualify and validate wear simulation devices and methods. Dent Mater 22:712-734

45. Caughman WF, Chan DC, Rueggeberg FA (2001) Curing potential of dual-polymerizable resin cements in simulated clinical situations. J Prosthet Dent 86:101-106

46. Kumbuloglu O, Lassila LV, User A, Vallittu PK (2004) A study of the physical and chemical properties of four resin composite luting cements. Int J Prosthodont 17:357-363

47. Braga RR, Cesar PF, Gonzaga CC (2002) Mechanical properties of resin cements with different activation modes. J Oral Rehabil 29:257-262

48. Wagner WC, Aksu MN, Neme AM, Linger JB, Pink FE, Walker S (2008) Effect of pre-heating resin composite on restoration microleakage. Oper Dent 33:72-78

49. Rueggeberg FA, Daronch M, Browning WD, De Goes MF (2010) In vivo temperature measurement: tooth preparation and restoration with preheated resin composite. J Esthet Restor Dent 22:314-322

50. Elsayad I (2009) Cuspal movement and gap formation in premolars restored with preheated resin composite. Oper Dent 34:725731

51. Daronch M, Rueggeberg FA, De Goes MF (2005) Monomer conversion of pre-heated composite. J Dent Res 84:663-667

52. Krejci I, Guntert A, Lutz F (1994) Scanning electron microscopic and clinical examination of composite resin inlays/onlays up to 12 months in situ. Quintessence Int 25:403-409

53. Rechenberg DK, Gohring TN, Attin T (2009) Influence of different curing approaches on marginal adaptation of ceramic inlays. J Adhes Dent 12(3):189-196

54. Bortolotto T, Doudou W, Stavridakis M, Ferrari M, Krejci I (2007) Marginal adaptation after aging of a self-etching adhesive containing an antibacterial monomer. J Adhes Dent 9:311-317

55. Dietschi D, Moor L (1999) Evaluation of the marginal and internal adaptation of different ceramic and composite inlay systems after an in vitro fatigue test. J Adhes Dent 1:41-56

56. Frankenberger R, Lohbauer U, Schaible RB, Nikolaenko SA, Naumann M (2008) Luting of ceramic inlays in vitro: marginal quality of self-etch and etch-and-rinse adhesives versus self-etch cements. Dent Mater 24:185-191

57. Krejci I, Lutz F, Reimer M (1993) Marginal adaptation and fit of adhesive ceramic inlays. J Dent 21:39-46

58. Dietschi D, Herzfeld D (1998) In vitro evaluation of marginal and internal adaptation of class II resin composite restorations after thermal and occlusal stressing. Eur J Oral Sci 106:1033-1042

59. Dietschi D, Olsburgh S, Krejci I, Davidson C (2003) In vitro evaluation of marginal and internal adaptation after occlusal stressing of indirect class II composite restorations with different resinous bases. Eur J Oral Sci 111:73-80

60. Hickel R, Manhart J (2001) Longevity of restorations in posterior teeth and reasons for failure. J Adhes Dent 3:45-64

61. Santini A, Milia E (2004) Microleakage around a low-shrinkage composite cured with a high-performance light. Am J Dent 17:118-122

62. Pashley DH (1989) Dentin: a dynamic substrate - a review. Scan Microsc 3:161-174, discussion 174-6 
63. Feilzer AJ, de Gee AJ, Davidson CL (1993) Setting stresses in composites for two different curing modes. Dent Mater 9:2-5

64. Denissen H, Dozic A, van der Zel J, van Waas M (2000) Marginal fit and short-term clinical performance of porcelain-veneered CICERO, CEREC, and Procera onlays. J Prosthet Dent 84:506-513

65. Dietschi D, Magne P, Holz J (1995) Bonded to tooth ceramic restorations: in vitro evaluation of the efficiency and failure mode of two modern adhesives. Schweiz Monatsschr Zahnmed 105:299-305

66. Dietschi D, Magne P, Holz J (1993) An in vitro study of parameters related to marginal and internal seal of bonded restorations. Quintessence Int 24:281-291

67. Sorensen JA, Munksgaard EC (1995) Ceramic inlay movement during polymerization of resin luting cements. Eur J Oral Sci 103:186-189

68. Manhart J, Chen HY, Mehl A, Weber K, Hickel R (2001) Marginal quality and microleakage of adhesive class V restorations. J Dent 29:123-130

69. Bortolotto T, Onisor I, Krejci I (2007) Proximal direct composite restorations and chairside $\mathrm{CAD} / \mathrm{CAM}$ inlays: marginal adaptation of a two-step self-etch adhesive with and without selective enamel conditioning. Clin Oral Investig 11:35-43

70. Hilton TJ, Schwartz RS, Ferracane JL (1997) Microleakage of four class II resin composite insertion techniques at intraoral temperature. Quintessence Int 28:135-144

71. Hugo B, Stassinakis A, Hofmann N, Hausmann P, Klaiber B (2001) In vivo study of small class II composite fillings. Schweiz Monatsschr Zahnmed 111:11-18

72. Mehl A, Kunzelmann KH, Folwaczny M, Hickel R (2004) Stabilization effects of CAD/CAM ceramic restorations in extended MOD cavities. J Adhes Dent 6:239-245
73. Reeh ES, Douglas WH, Messer HH (1989) Stiffness of endodontically-treated teeth related to restoration technique. J Dent Res 68:1540-1544

74. Richter J, Mehl A (2006) Evaluation for the fully automatic inlay reconstruction by means of the biogeneric tooth model. Int $\mathrm{J}$ Comput Dent 9:101-111

75. Ender A, Mormann WH, Mehl A (2010) Efficiency of a mathematical model in generating CAD/CAM-partial crowns with natural tooth morphology. Clin Oral Investig 15(2):283-289

76. Edelhoff D, Sorensen JA (2002) Tooth structure removal associated with various preparation designs for posterior teeth. Int J Periodontics Restorative Dent 22:241-249

77. Edelhoff D, Sorensen JA (2002) Tooth structure removal associated with various preparation designs for anterior teeth. J Prosthet Dent 87:503-509

78. Pippin DJ, Mixson JM, Soldan-Els AP (1995) Clinical evaluation of restored maxillary incisors: veneers vs. PFM crowns. J Am Dent Assoc 126:1523-1529

79. Magne P, Kim TH, Cascione D, Donovan TE (2005) Immediate dentin sealing improves bond strength of indirect restorations. J Prosthet Dent 94:511-519

80. Ito S, Hashimoto M, Wadgaonkar B, Svizero N, Carvalho RM, Yiu C et al (2005) Effects of resin hydrophilicity on water sorption and changes in modulus of elasticity. Biomaterials 26:6449-6459

81. Frankenberger R, Lohbauer U, Taschner M, Petschelt A, Nikolaenko SA (2007) Adhesive luting revisited: influence of adhesive, temporary cement, cavity cleaning, and curing mode on internal dentin bond strength. J Adhes Dent 9(Suppl 2):269273 